\title{
P2P \& LBS Technology-Based Mobile Police System Design
}

\author{
Wei Yao1, Ping $\mathrm{He}^{2}$, Song $\mathrm{Xu}^{1}$ \\ ${ }^{1}$ Anshan Public Security Bureau, Anshan, China \\ ${ }^{2}$ Liaoning Police Academy, Dalian, China \\ Email: heping2000@126.com, xusong67007@126.com
}

Received 8 August 2015; accepted 12 September 2015; published 15 September 2015

Copyright (C) 2015 by authors and Scientific Research Publishing Inc.

This work is licensed under the Creative Commons Attribution International License (CC BY). http://creativecommons.org/licenses/by/4.0/

\section{(c) (i) Open Access}

\begin{abstract}
With the coverage by the mobile network and the popularization of mobile phone communication software, the traditional voice communication, short message service and even the interconnection service have gradually been replaced by mobile terminal equipment. Confronted with the ever-increasingly serous information explosion, police authorities meet with new challenges in their daily police work. This paper establishes a mobile police application system integrating office work, early warning, publicity and surveillance through careful study of the Peer to Peer and Location Based technology, striving to transform the traditional idea, break the traditional mode, expand the tradition scope so as to better exercise the social supervision function, publicize precaution information and crack down on crime.
\end{abstract}

\section{Keywords}

Peer to Peer, Location Based Service, Mobile Police System

\section{Introduction}

With the substantial coverage of the mobile communication network, especially the recent successful operation of 4G communication technology, future mobile network technology will increase exponentially. In the meantime, traditional police work cannot meet the demand of the public for efficiency, convenience and professionalism. It can be predicted that electronic police will take the place of artificial police entirely in the future, which will not only simplify the process of handling public security businesses for the public but also significantly reduce the cost. The mobile police application system will become one of the major carriers of police work in the future.

Peer to Peer network (P2P), also called Peer to Peer connection, is a new communication mode. Each partici- 
pant is endowed with the same capacity to start a communication conversation [1]. The P2P network is uniquely characterized by decentralization, extensibility, robustness, high performance-price ratio, privacy protection and load balance, triggering the interest of various research institutions across the world. Large numbers of P2P applications are constantly on the rise [2].

At present, most mobile communication software employs P2P technology to realize communication between users through text, picture, voice and video. It can be said that the earliest real-time communication system starts from ICQ. Mirabilis Company established in 1996 launched the first real-time communication software-ICQ. From then on, real-time communication software became popular around the globe. Those widely applied include MSN, Yahoo Messenger, QQ, AIM and Skype.

Location Based Service (LBS) is a value added service that provide relevant services to users by obtaining position information (geological coordinates or geodetic coordinates) of mobile terminal users through the telecommunication network of telecommunication mobile operators (such as GSM, CDMA) with the support of GIS (Geographic Information System) platform [3].

It has two meanings: the first is to determine the geological position of mobile equipment or users; and the second is to provide various kinds of information related to the position. It refers to various service systems related to positioning, or "location service"; it can also be called MPS-Mobile Position Services, or "mobile positioning service" system [4].

Mobile police has gone through three development stages. The first generation mobile office access technology based on short messages has been eliminated because it is not so good in real-time performance and response cannot be immediately given for enquiries. The second generation mobile Jingwutong system employs the WAP technology based method and mobile phones access WAP web pages through browsers to realize information enquiry. Its defects mainly include its extremely poor interaction performance in WAP webpage access, significantly limiting the flexibility and convenience of the mobile Jingwutong system. The third generation mobile Jingwutong system integrates a number of latest cutting-edge technologies in mobile communication, information processing and computer network such as 3G mobile technology, smart mobile terminals, VPN, database synchronization, ID certification and Web service, serving as a widely applied mobile police system [5].

This paper designs a set of highly integrated and efficient mobile police comprehensive application system by analyzing shortcomings and defects of the traditional police work and combining technical features of P2P and LBS. In the meantime, the feasibility and superiority of the system is proved through detailed demonstration and field experiment.

The paper is structured as follows: we present the relevant studies in Sections 2. Section 3 contains the author's main ideas on study of Peer to Peer and Location Based service based mobile police application system. Experimental comparisons of new mobile police system and traditional police work, which are discussed in Section 4. Finally, Section 5 contains the main conclusions and prospects.

\section{Mobile Police Application System}

Although mobile police has been through three stages with remarkable progress accomplished, the basic requirement that the mobile police shall cover all public security activities is neglected. The trend for mobile police does not just enable police officers to use it but shall involve the whole society. Therefore, this paper proposes a new mobile police system model based on the corporate management mode by combining Peer to Peer and Location Based service technology.

\subsection{Mobile Police System Model}

The new mobile police system consists of four subsystems. The window service and legal knowledge publicity system and case and corruption reporting system realizes zero distance contact with the public mainly by taking advantage of Peer to Peer technology. In the meantime, the case reporting system employs the port data connection to realize seamless connection between interconnected data with public security data. In the police command and combat system, real-time dispatching is realized by linking to the geological information platform and integrating information obtained through LBS technology. Finally, in the case investigation and auxiliary system, by monitoring server data and information obtained through LBS technology, relevant clues can be provided to public security authorities effectively and, even better, the purpose of accurate positioning and fighting crime can be realized. The model is shown in bellowing: 
Mobile police system $\left\{\begin{array}{c}\text { Window service and legal knowledge publicity system case and corruption reporting system } \\ \text { Police direction and combat system }\end{array}\right.$

\subsection{Window Service and Legal Knowledge Popularization}

Window service is a reflection of the exercise of the social supervision function by public security authorities and is most closely related to the public. The new mobile police comprehensive application system creates an efficient, convenient and flexible mobile police terminal by repeatedly studying the demand of the public on the public security window service and boldly introducing relevant techniques such as two dimensional codes, ID information acquisition and promote this service through mobile phone software operators. The functions realized are shown in Figure 1.

\subsubsection{Reservation and Enquiry through Window Service}

With this system, the public may reserve relevant public security services through mobile phone or computer. To put is simply, the public can login the P2P server side terminal through mobile phone or connect to relevant website through computer to upload personal information to the server by filling out relevant information or taking photos. The client-side will rationally arrange reservation time based on the completeness of user information and the workload that can be handled each day and feed back the two dimenstional code to the user, thereby realizing the purpose of reservation. In the meantime, the user can contact customer service to enquire about relevant questions through the client-side. The procedure is shown in Figure 2.

\subsubsection{Case Information Communication}

Cracking down on crime is the core function of the public security authorities. Traditional case communication requires the persons involved to go through relevant procedures at the public security office, which significantly affects case confidentiality and flexibility. With this system, the persons involved may learn about the latest progress and information about relevant case handling officers anytime through the terminal based on case number; or they can feed back case clues to the case handling officers at any time. The procedure is shown in Figure 3.

\subsection{Case and Corruption Reporting System}

Citizens have the obligation to report illegal activities and crimes to public security authorities timely and only

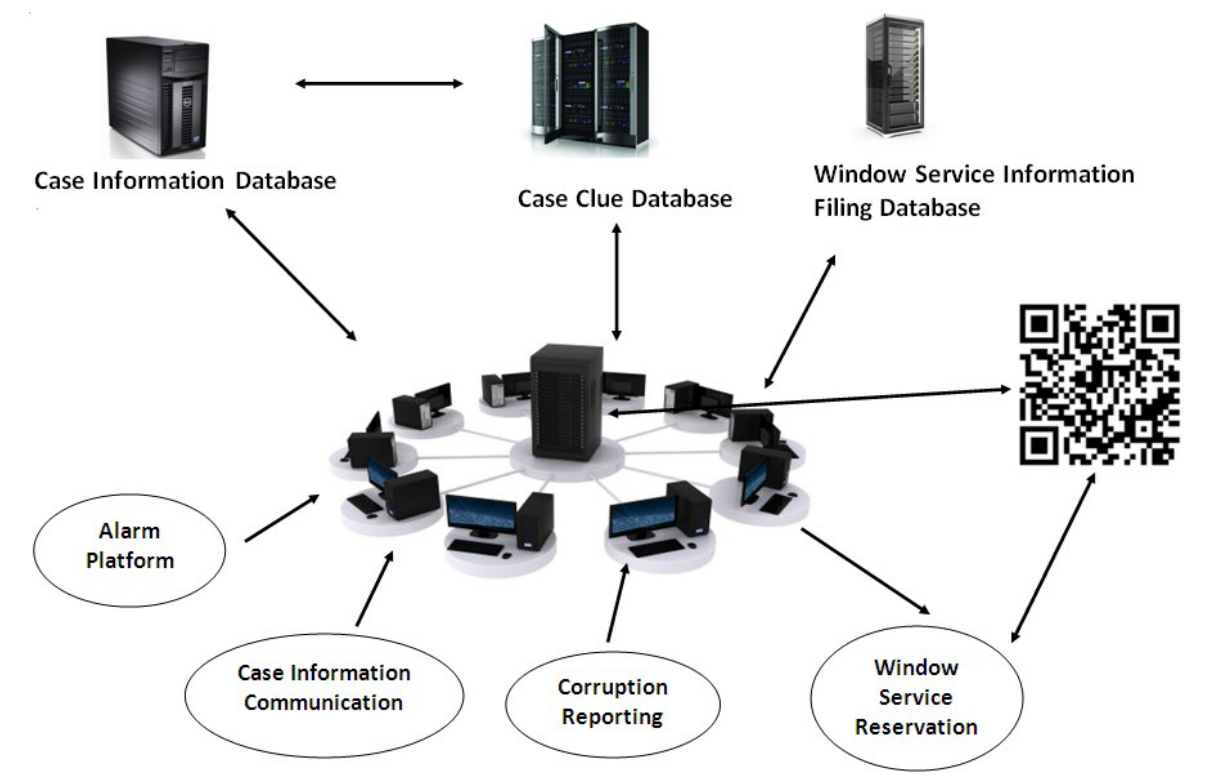

Figure 1. Window service and legal knowledge publicity system data circulation schematic diagram. 


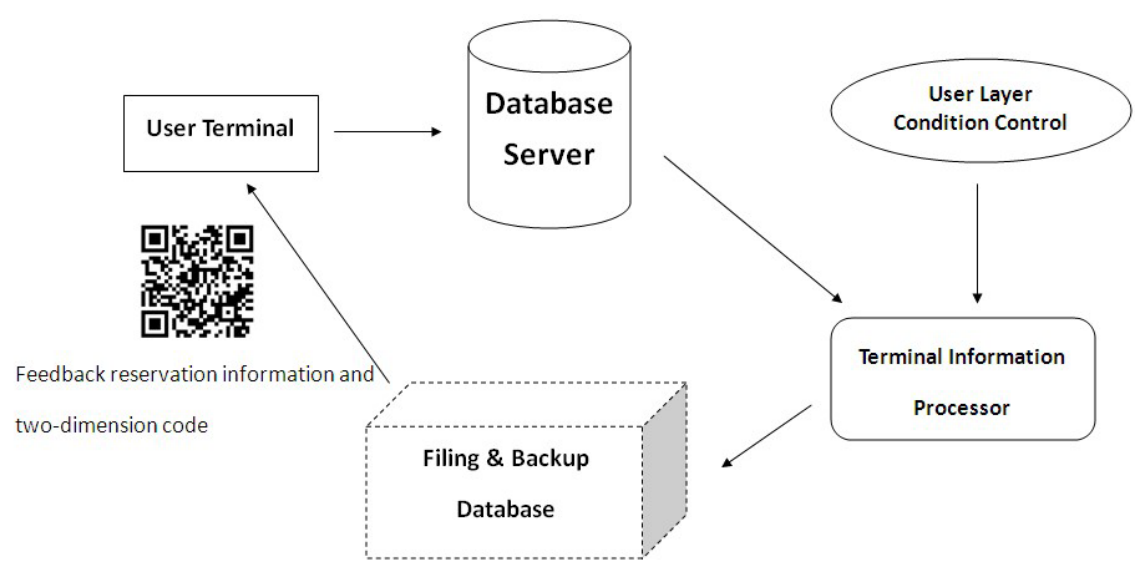

Figure 2. Window reservation procedure schematic diagram.

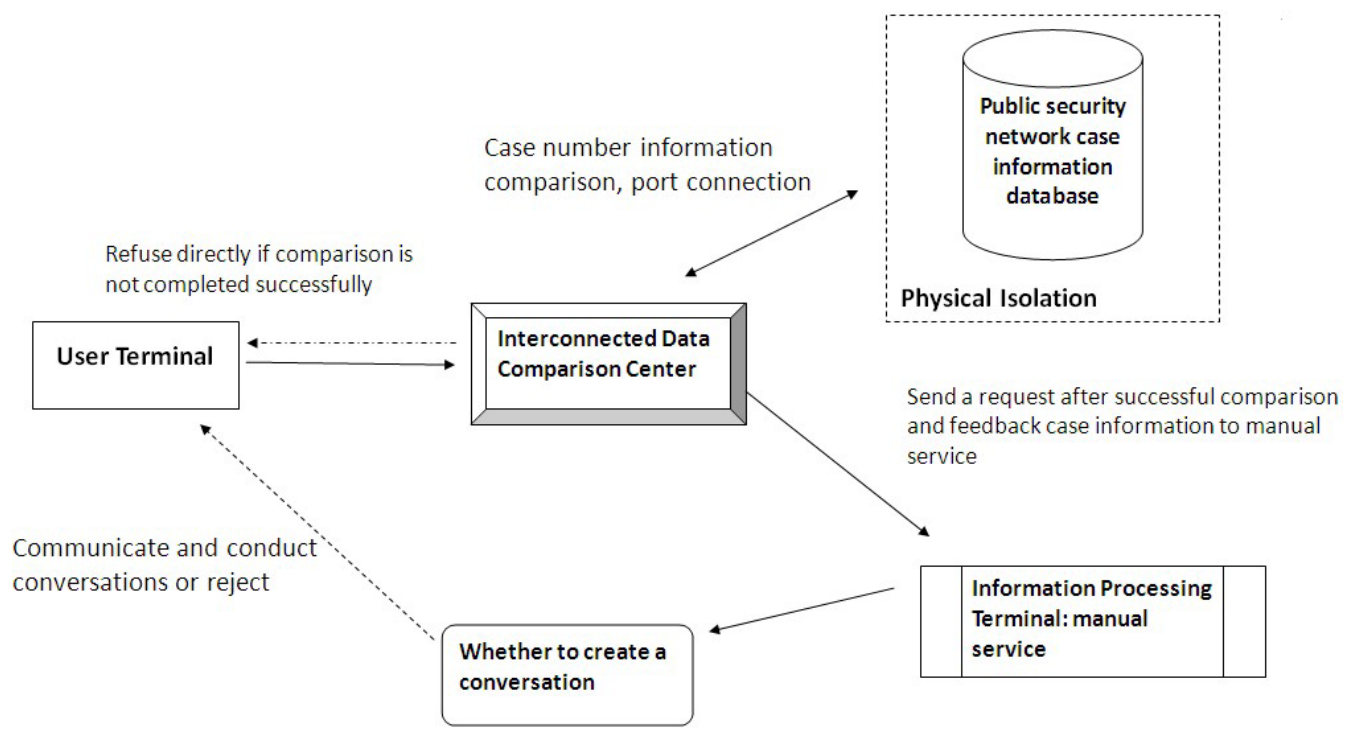

Figure 3. Case informational linkage procedure schematic diagram.

through reporting can the situation relating to their own interests be solved in a legal manner. Therefore, case reporting is the most important link in daily police activities. Traditional reporting methods include calling 110 or reporting directly at case handling units. But a lot of people are unwilling to take the trouble to report illegal activities to public security authorities, which significantly restricts the timeliness of fighting crime. This system provides a fast and convenient case reporting channel to citizens through P2P and LBS technology and provides information about the nearest police station using the LBS positioning technology so as to facilitate timely dispatching of police force and case reporting.

\subsubsection{Many-to-One Case Reporting System Design}

The so called many-to-one case reporting system means that all users can report a case to a designated public security authority client-side through their client-side, equivalent to the traditional reporting method by 110 . Unlike the traditional method, with the support of the P2P technology, users can use voice, texts, video and even real-time video to restore case scenes [6]. The procedure is shown in Figure 4.

\subsubsection{Many-to-Many Case Reporting System Design}

The so called many-to-many case reporting system realizes nearby case reporting based on LBS technology through attached police workstation. To put it simply, users can use the nearest reporting function and find the nearest police workstation to realize case reporting directly. The application examples are shown in Figure 5. 


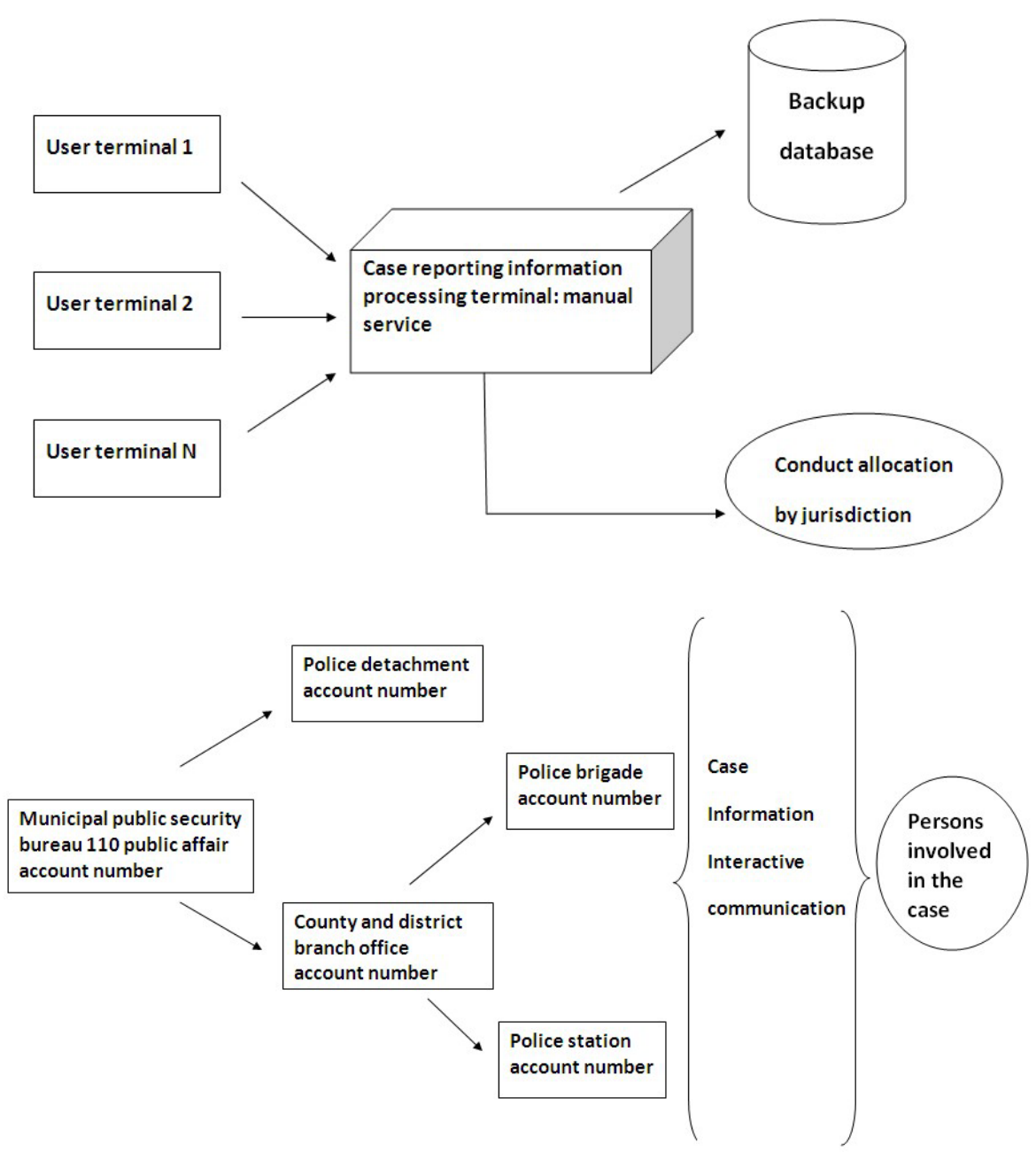

Figure 4. Many-to-one case reporting system flow chart and case clue circulation schematic diagram.

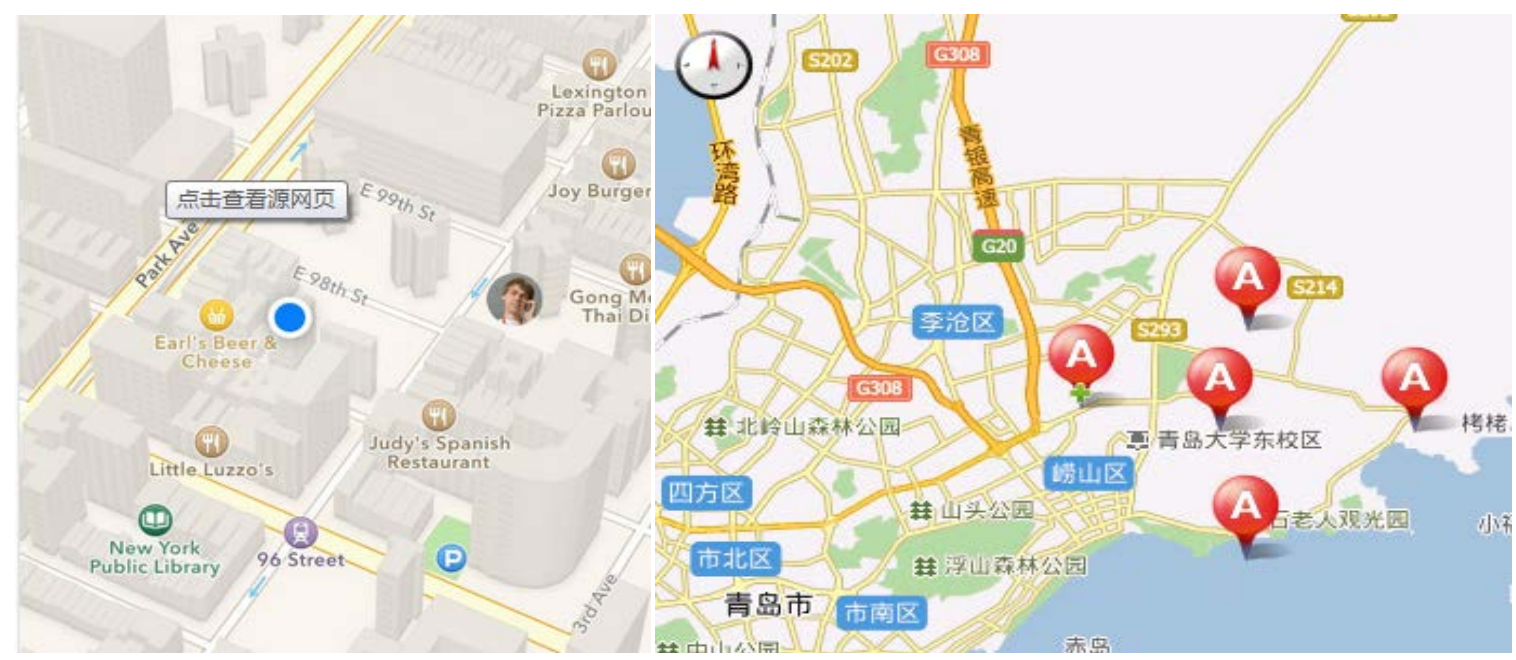

Figure 5. LBS positioning technique based software view examples.

2.3.3. Corruption Reporting Function

Corruption supervision is the right and obligation of citizens. Users can use the client-side to contact public se- 
crudity discipline inspection department to report issues such as operation conducted by relevant case handling units against rules, which not only ensures that reporting made by the public can directly reach the discipline inspection department but also reduces the number of petitioners so as to maintain local stability.

\subsection{Police Command and Combat System}

Police dispatch has always been a difficulty facing public security authorities. At present, the main solution is to use the GPS position finder and carry out communication by telephone. GPS position finder is complicated in operation and contact by telephone is severely restrictive and lagging [7]. The police command and combat system combines police geological information application platform with mobile phone software via port connection to know the specific position of police officers at any time using the LBS positioning technology and, in the meantime, it can give latest orders and feedback through the client-side. The procedure is shown in Figure 6.

In the meantime, the police command and combat system sends instructions to various units using the P2P technology. P2P supports multiple users on line simultaneously and temporary command posts can be set up by simulating video meetings, voice meetings, text meetings, etc. Please see Figure 7.

\section{Primary Algorithm and Program Analysis of Mobile Police System}

Before you begin to format your paper, first write and save the content as a separate text file. Keep your text and graphic files separate until after the text has been formatted and styled. Do not use hard tabs, and limit use of hard returns to only one return at the end of a paragraph. Do not add any kind of pagination anywhere in the paper. Do not number text heads - the template will do that for you.

Finally, complete content and organizational editing before formatting. Please take note of the following items when proofreading spelling and grammar.

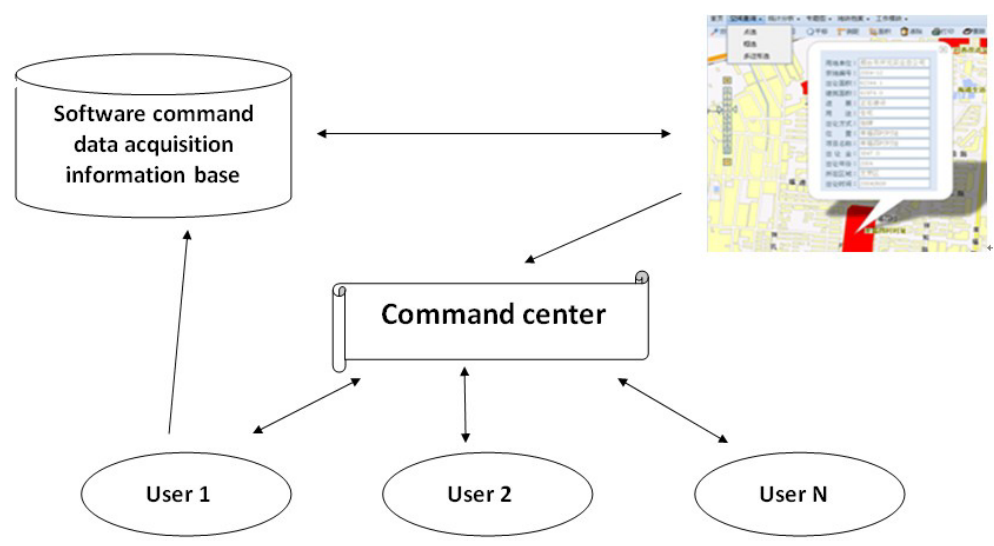

Figure 6. Police command \& positioning system schematic diagram.

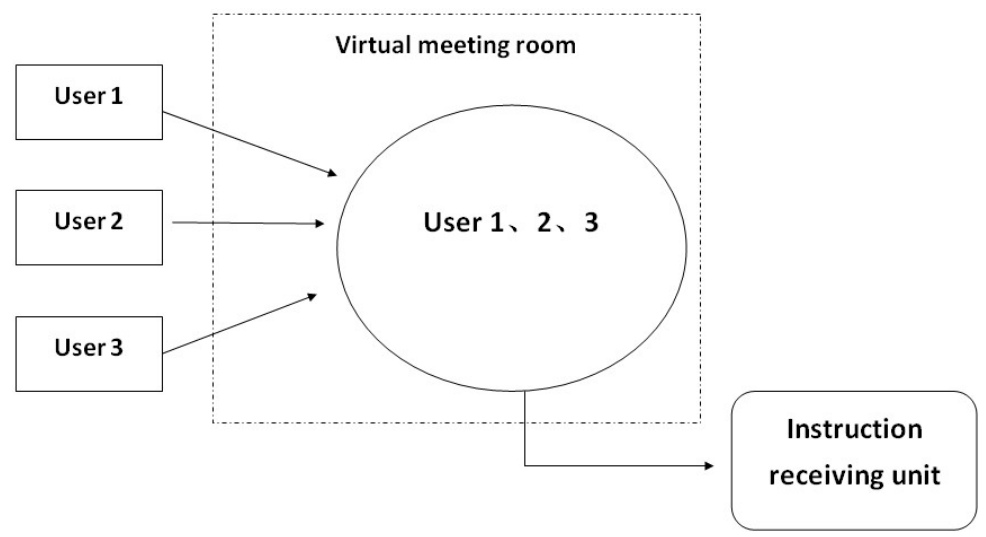

Figure 7. Police command system virtual command schematic diagram. 


\subsection{Mobile Police System Interactive Design Analysis}

The mobile comprehensive application system that is based on P2P and LBS technology represents the trend for the development of future police work. The police system designed in this paper takes into account current mainstream mobile phone software features and modern informationized police requirements and its basic functions are designed using $\mathrm{C}++$ and JAVA language. In the meantime, establishment of the system strictly follows the distributed program design concept to make subsystems of the software independent and unified. Primary algorithm of the system includes client-side connection, database connection and mobile positioning. The overall design of the system is shown in Figure 8.

\subsection{Mobile Police System Port Connection Code Examples}

To put it simply, police work is comprehensive reflection of daily government affairs and social supervision conducted by public security authorities. It is the power vested by the state and serves as the basis to guarantee regional stability and fight crime. Traditional police work mainly includes window service, case handling and police command as shown in Table 1.

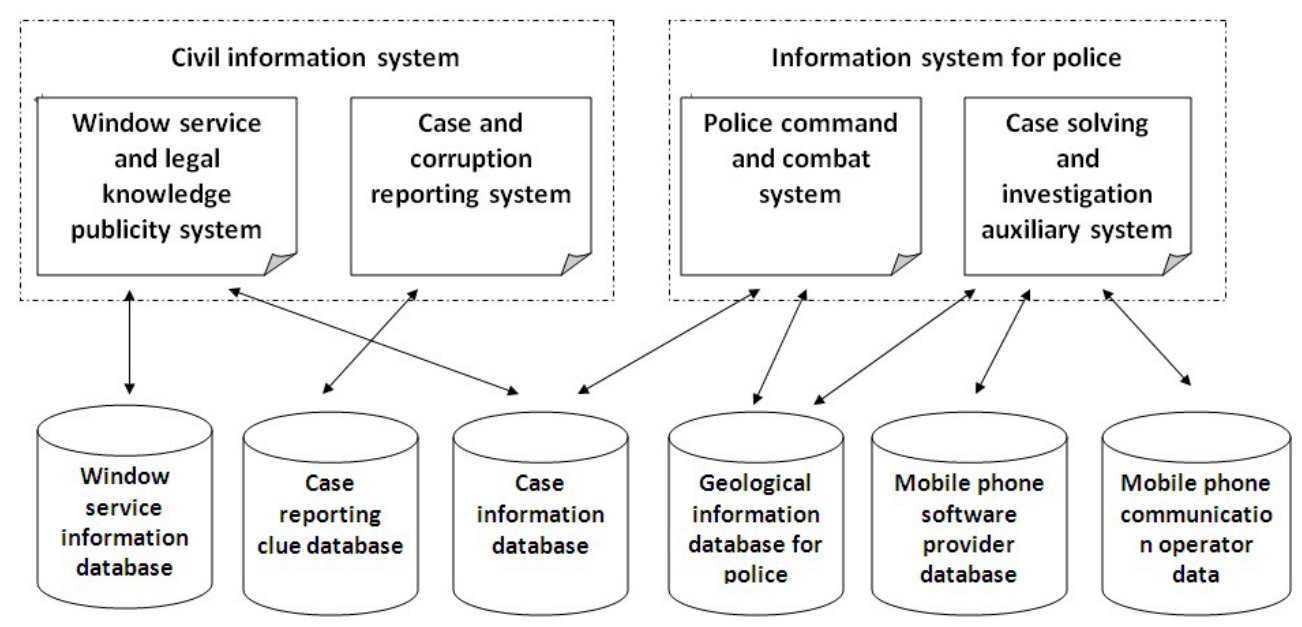

Figure 8. Mobile police system interaction design schematic diagram.

Table 1. Traditional police work basic scope schematic diagram.

\begin{tabular}{l} 
Window service \\
1. Passport approval and handing \\
2. ID card approval and handing \\
3. Passport and ID card loss reporting and re-issue service \\
4. Household register and temporary residence permit handing \\
5. Special trade approval and management \\
6. Judicial expertise reservation and handing \\
7. Traffic violation and relevant services \\
8. Vehicle approval and relevant services \\
Case handing \\
1. Case reporting \\
2. Case information communication \\
3. Notification of case related information \\
Police transfer \\
1. Internal information communication \\
2. Combat command just before a war \\
\hline
\end{tabular}


Through long term exploration, public security authorities have developed a relevantly perfect work procedure and business handling method. However, with the coming of the information age, traditional police cannot meet the demand of the public for highly efficient, convenient and simple police activities [8]. At present, main urgent issues to be solved by public security authorities include:

1) Approval procedures for relevant affairs related to public security are tedious and complex and most window services require handling in person.

2) People have to line up when handling matters with no unified sequence and there are a number of artificial factors involved.

3) Cases are not handled in a transparent manner and much information is not relayed effectively.

4) Corruption supervision is not adequate, which tends to give rise to petitions or even mass incidents.

5) The police command mode is too simple, dispatch and command cannot be conducted smoothly and there is a possibility of divulging secrets during actual combat.

6) Expenses of paper, equipment and labor are huge and lagging is severe.

\subsection{Field Analysis Table Regarding New Mobile Police Comprehensive Application System and Traditional Police Work}

Experiment place: Anshan Public Security Bureau, Tiedong Branch, Hunan Police Station.

Experiment subject: carry out work using the new mobile police system for a month.

Experiment purpose: compare work conducted using the new mobile police system for a month with work conducted at the same corresponding period. Experiment result: As shown in Table 2.

From the above table, we can obviously see that average number of people who successfully handle household registration and various approvals increased by $186 \%$ and $143 \%$ respectively after using the new mobile police system for a month, that is to say, within the same time limit, the high efficiency of e-police bring up the number in a significant manner. In the meantime, number of case reporting, enquiry, police officer dispatching and telephone reception per day decreases remarkably and a great deal of work can be accomplished through the mobile police platform. Owing to this, costs are reduced substantially by almost $50 \%$ for paper, oil consumption and overtime.

\section{Table 2. Experiment result.}

\begin{tabular}{|c|c|c|c|}
\hline \multicolumn{4}{|c|}{$\begin{array}{l}\text { Comparison of mobile police work from January to February of } 2014 \text { with traditional } \\
\text { police work for the same corresponding period of } 2013\end{array}$} \\
\hline No. & Item & Traditional police work mode & New mobile police system \\
\hline 1 & Number of people that successfully handle household registration per day & 5.7 people & 16.3 people \\
\hline 2 & Average time needed to handle house registration & $1.5 \mathrm{~h}$ & $17 \mathrm{~min}$ \\
\hline 3 & Number of people that come to the police station to report a case & 27.5 people & 12.3 people \\
\hline 4 & Number of people that come to the police station to be questioned per day & 19.7 people & 6.5 people \\
\hline 5 & $\begin{array}{l}\text { Number of people whose various kinds of applications are successfully } \\
\text { handled per day }\end{array}$ & 3.2 people & 7.8 people \\
\hline 6 & Average time needed to handle various approvals & $3.1 \mathrm{~h}$ & $1.2 \mathrm{~h}$ \\
\hline 7 & Police officer dispatching times per day & 37.5 times & 13.3 times \\
\hline 8 & Total pieces of information imported per day & 64.3 pieces & 124.5 pieces \\
\hline 9 & Oil consumption of police cars dispatched per day & $37.6 \mathrm{~L}$ & $17.8 \mathrm{~L}$ \\
\hline 10 & Office paper needed per day & 138.6 pieces & 47.5 pieces \\
\hline 11 & Min. number of office workers required per day & 16.7 people & 7.8 people \\
\hline 12 & Number of calls received per day & 132.2 person-time & 69.5 person-time \\
\hline 13 & Total office hours of police officers required per day & $137 \mathrm{~h}$ & $89 \mathrm{~h}$ \\
\hline 14 & Total average overtime hours of police officers per day & $46 \mathrm{~h}$ & $21 \mathrm{~h}$ \\
\hline 15 & Total average daily expenses of various kinds & 2725.6 Yuan & 1353.6 Yuan \\
\hline
\end{tabular}




\section{Conclusion and Prospect}

Based on the field experiment, the results are shown in Figure 9 and Figure 10. We can see changes in police work brought about by the new mobile police system through comparison:

1) Substantially increase window service efficiency and reduce office work cost. The new mobile police system combines advanced technologies such as two-dimensional code and P2P and changes the traditional lining up mode to reservation on time, which not only alleviates the burden on citizens for making applications but also increases affair handling success rate. In the meantime, citizens can print reservation documents directly according to two dimensional codes, remarkably reducing the use of paper as well as the number of window service personnel.

2) Reduce police dispatch and reception time and release the police labor force. The new mobile police system supports seamless interaction between police officers and citizens by sending text, picture and video related to information concerned or even by replacing traditional enquiry and appointment with voice dialog and video calls, which not only increases the flexibility of case handling by police officers but also saves the general masses from being busy running about.

3) Ensure information integrity and reduce expenses of various kinds. The new mobile police system automatically stores various kinds of information, thus avoiding repeated entry by police officers and solving the issues of paper, oil consumption and overtime so as to reduce various expenses significantly.

In order to show the changes in actual work efficiency and cost in a visual manner, the following curve comparison is obtained through analysis of data of each day in a month.

Through the comparison of both efficiency and cost, we can easily see that the new mobile police system can remarkably increase efficiency and reduce cost. The introduction of the new mobile police system can not only increase the efficiency of daily police activities but bring convenience and benefit to the people.

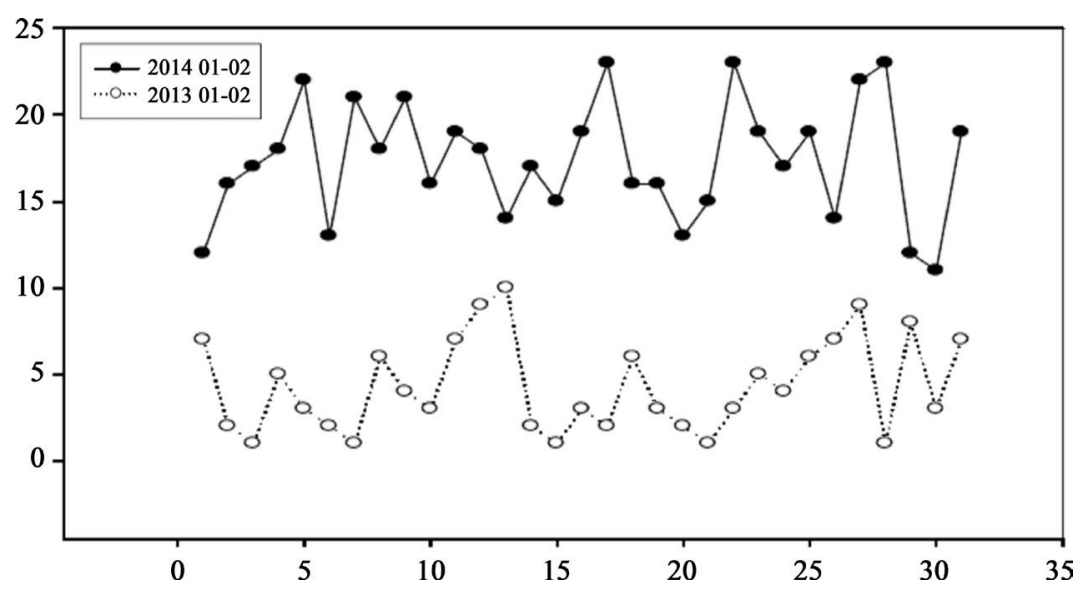

Figure 9. Comparison chart regarding the number of daily handled matters by mobile police and traditional police.

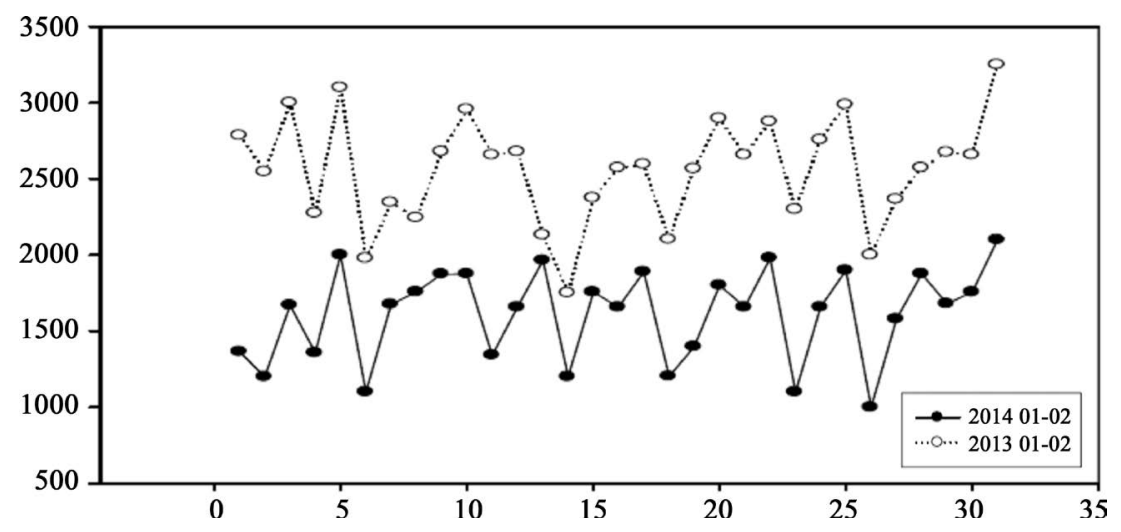

Figure10. Comparison chart regarding daily cost of mobile police and traditional police. 


\section{References}

[1] American Mathematical Society (2004) AMS-LaTeX Version 2 User’s Guide. P2P Technology, Baidu Baike, AMS. http://www.ams.org/tex/amslatex.html

[2] Iyong and Du, Y.L. (2011) Survey of DHT Search Algorithm in Peer-to-Peer Network. Northwestern Polytechnical University School of Computing, Xi'an.

[3] Zhang, C.H. (2010) Comprehensive Analysis of P2P Technology. People’s Posts and Telecom Press.

[4] Kupper, A. (2005) Ludwig Maximilian University Munich, Germany Location-Asked Services: Fundamentals and Operation. John Wiley \& Sons Ltd., Hoboken.

[5] Stoica, I., Morris, R., Karger, D., et al. (2001) Chord: A Scalable Peer-to-Peer Lookup Service for Internet Applications. Proceedings of ACM SIGCOMM, 27-31 August 2001, ACM, San Diego, New York, 149-160.

[6] de Candia, G., Hastorun, D., Jampani, M., et al. (2007) Dynamo: Amazon’s Highly Available Key-Value Store. Proceedings of 21st ACM SIGOPS Symposium on Operating Systems Principles, 14-17 October 2007, ACM, New York, 205-220.

[7] Jennings, C., Lowekamp, B.B., Rescorla, E., et al. (2009) Resource Location and Discovery (RELOAD) Base Protocol. draft-ietf-p2psip-base-02 [EB/OL]. http://www.ietf.org

[8] Das, S., Swaminathan, A. and Narayanan, V. (2009) A Load Balancing Mechanism for Resource Location and Discover. draft-saumitra-p2psip-loadbalance-00 [EB/ OL]. http://www.ietf.org 